\title{
Agôn
}

Revue des arts de la scène

Critiques | Saison 2010-2011

\section{Ceci n'est pas une critique}

Plus loin que les étoiles, mise en scène de Marta Gil Polo

\section{Caroline Châtelet}

\section{(2) OpenEdition \\ 12 Journals}

Édition électronique

URL : http://journals.openedition.org/agon/1839

DOI : 10.4000/agon.1839

ISSN : 1961-8581

Éditeur

Association Agôn

Référence électronique

Caroline Châtelet, « Ceci n'est pas une critique », Agôn [En ligne], Critiques, mis en ligne le 28 mai 2011, consulté le 23 septembre 2020. URL : http://journals.openedition.org/agon/1839 ; DOI : https:// doi.org/10.4000/agon.1839

Ce document a été généré automatiquement le 23 septembre 2020

Association Agôn et les auteurs des articles 


\title{
Ceci n'est pas une critique
}

Plus loin que les étoiles, mise en scène de Marta Gil Polo

\author{
Caroline Châtelet
}

\section{RÉFÉRENCE}

Plus loin que les étoiles

idée originale et mise en scène Marta Gil Polo

texte de Marta Gil Polo et Albert Tola

spectacle vu à l'occasion du Festival Théâtre en Mai, à Dijon - www.tdb-cdn.com

Théâtre des Feuillants - du mercredi 25 au jeudi 26 mai

1 Ceci n'est pas une critique. Ou plutôt, ceci, quel que soit son propos, ne peut pas être une critique. Parce qu'ayant seulement assisté à la répétition générale de Plus loin que les étoiles, les lignes suivantes sont un regard sur un spectacle encore à venir, créé à l'occasion du festival Théâtre en Mai, à Dijon. Impossible, donc, que la pratique critique s'exerce dans ce temps qui précède la représentation, ce moment d'avant le théâtre. Le théâtre advient lors de la rencontre avec un public, pas avec les happy few, membres ou proches de l'équipe artistique conviés à une répétition. Bon, alors, pourquoi cette précision sur la forme de ce texte ? Peut-être parce qu'elle résonne avec son propos. Et que si cet écrit n'est pas une critique, il traite d'un spectacle dont l'objet réel semble se nicher dans sa propre absence, dans ce qu'il ne montrera pas du sujet abordé. Comme Marta Gil Polo le dit dans une note d'intention: «Michael Jackson m'accompagne depuis mon enfance, lorsque je dansais à l'écoute de ses chansons. Je n'ai pas pu résister à la tentation de faire un spectacle sur lui. » Faisant cela, la jeune metteur en scène espagnole propose une variation sur la figure du « Roi de la Pop ». Plus loin que les étoiles réunit ainsi dans une succession de séquences chantées ou jouées des temps de vies de Michael Jackson. Réelles ou imaginaires, ces saynètes évoquent très simplement son enfance, ses liens avec ses parents, ses frères, la carrière des Jackson Five, la sienne en solo, les accusations de pédophilie ou encore l'attachement déraisonné à sa mère. Autant de pièces autonomes d'un puzzle qui refuse de se laisser terminer. Car dans l'interprétation vivante qu'offrent les quatre comédiens-sosies de Michael Jackson, tout 
semble à chaque fois se dérober. Ainsi, le dédoublement des dialogues entre la star et sa mère souligne autant l'aspect malsain et fusionnel de ces relations que le fantasme qui les entoure. De même avec la narration à l'identique des différentes accusations de pédophilie ou lors des récurrentes altercations avec le père. Travaillant dans un dispositif dont la simplicité accentue la réception directe du propos, la metteur en scène ne réunit que des clichés. Si ce choix pourrait désigner l'échec de l'équipe à dépasser l'histoire connue de la star, la structure cyclique et répétitive affirme et assume cette position. La vie réelle, les motivations et pensées intimes de Michael Jackson sont les pièces définitivement manquantes de ce jeu de construction, qui nous échappent à tous. Les reconstitutions caricaturales des coups d'éclats et scandales ayant émaillé la vie du chanteur désignent au final en creux ce qui demeurera à jamais inconnu. Plus loin que les étoiles révèle ainsi, par le biais de l'exposition d'une existence soumise à sa propre image médiatique, l'éternelle résistance du sujet Michael Jackson à sa propre histoire.

INDEX

Mots-clés : Gil Polo (Marta), Tola (Albert), Plus loin que les étoiles, Théâtre en Mai, Dijon 